\title{
Automatic regulation of the cuff pressure in endotracheally- intubated patients
}

\author{
R. Farré*, M. Rotger*, M. Ferrer", A. Torres", D. Navajas*
}

Automatic regulation of the cuff pressure in endotracheally-intubated patients. $R$. Farré, M. Rotger, M. Ferrer, A. Torres, D. Navajas. C ERS Journals Ltd 2002.

ABSTRACT: To avoid tracheal wall damage or inadvertent falls of the endotracheal tube cuff pressure $(P$ cuff) in intubated and mechanically-ventilated patients, the authors devised a simple procedure for automatic and continuous regulation of $\boldsymbol{P}$ cuff.

The procedure, only requiring a simple aquarium air pump and conventional tubing, was first tested at the bench when applied to an intubated and ventilated lung model, including an artificial trachea with an externally-variable section. The clinical performance of the procedure was tested in eight intubated patients, in whom the endotracheal tube cuff was connected to the designed $P$ cuff regulator during $24 \mathrm{~h}$.

The bench test showed that the procedure was able to maintain Pcuff constant, regardless of the changes imposed in the tracheal section. It was also effective in maintaining $\boldsymbol{P}$ cuff during routine mechanical ventilation. Actual $\boldsymbol{P}$ cuff recorded over the 24-h period always coincided with the target value within $\pm 2 \mathrm{cmH}_{2} \mathrm{O}$ in all the patients.

The procedure devised to maintain endotracheal tube cuff pressure is readily implemented, cheap, easy to operate and can be used regardless of the specific ventilator or tube used. Routine implementation of this procedure may be useful for protecting the trachea from tissue damage and for reducing the risk of ventilator-associated pneumonia.

Eur Respir J 2002; 20: 1010-1013.
*Unitat de Biofísica i Bioenginyeria, Facultat de Medicina, Universitat de Barcelona, and " Institut Clínic de Pneumologia i Cirurgia Toràcica, Hospital Clinic Provincial, Institut d'Investigacions Biomèdiques August $\mathrm{Pi}$ Sunyer, Barcelona, Spain.

Correspondence: R. Farré, Unitat de Biofisica i Bioenginyeria, Facultat de Medicina, Casanova 143, E-08036 Barcelona, Spain.

Fax: 34934024516

E-mail: farre@medicina.ub.es

Keywords: Endotracheal intubation, mechanical ventilation, monitoring artificial ventilation, nosocomial pneumonia, tracheal tissue damage

Received: December 212001

Accepted after revision: April 62002

The present study was supported by Comisión Interministerial de Ciencia y Tecnología (CICYT; SAF99-0001) and Dirección General de Enseñanza Superior e Investigación Científica (DGESIC; PM98-0027).
Ventilator-associated pneumonia (VAP) is the most relevant complication in mechanically-ventilated patients, given its high incidence, associated morbidity and mortality, and economic cost [1-3]. The most important pathogenic mechanism of VAP is the aspiration to the lower airways of contaminated secretions pooled above the endotracheal tube cuff [4]. Maintaining adequate inflation pressure of the endotracheal tube cuff $(P$ cuff $)$ is a key factor in the management of the patient/ventilator interface during invasive mechanical ventilation [5-7]. An excessively inflated cuff reaching $P$ cuff levels above the mucosal capillary pressure [8], although not frequent when using endotracheal tubes with a high-volume lowpressure cuff, has recently been reported to cause ischaemic tracheal wall injury [9]. Moreover, loss of cuff inflation is a much more frequent complication $[10,11]$. Persistently low $P$ cuff has been identified as a risk factor for VAP [11]. Consequently, ensuring a correct inflation of the endotracheal tube cuff has been recommended [4].

Routine management of $P$ cuff in intubated patients is generally performed by manually checking with a periodicity of several hours, which does not ensure adequate $P$ cuff maintenance during continuous endotracheal intubation [11]. Furthermore, manual checking of $P$ cuff may result in the aspiration to the lower airways of contaminated secretions pooled above the cuff. To avoid these problems, the authors devised and tested a simple procedure for automatically and continuously ensuring adequate $P$ cuff in the intensive care unit (ICU) environment.

\section{Methods}

The present authors devised a simple procedure for continuously and automatically regulating $P$ cuff in mechanically-ventilated patients (fig. 1). This system shares the same principle of continuous positive airway pressure devices, since the pressure applied to the cuff is generated by the passage of an airflow through a resistor. A small $\left(8 \times 4 \times 4 \mathrm{~cm}^{3}\right)$, low cost $(<12$ Euros) aquarium air pump (Nathura MK-701, $2.5 \mathrm{~W}$; ECIS, Bressanvido, Italy) generated a pulsating flow with an amplitude determined by a simple 


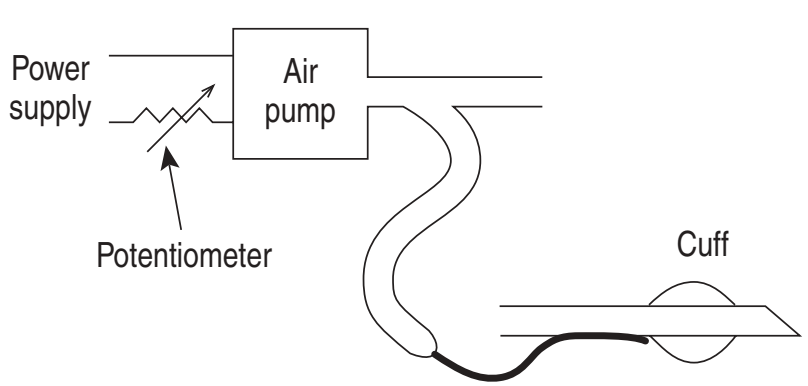

Endotracheal tube

Fig. 1.-Diagram of the cuff pressure regulation system. A domestic aquarium air pump is connected to the main power supply $(110 / 220 \mathrm{~V})$. The voltage provided to the pump is determined by means of a resistive potentiometer. The air outlet of the pump is connected to a leak tube $(9 \mathrm{~cm}$ in length, $1 \mathrm{~mm}$ in diameter) open to the atmosphere and to a flexible tube $(2 \mathrm{~m}$ in length, $2 \mathrm{~mm}$ diameter), allowing the pump be placed at a convenient distance from the endotracheally-intubated patient.

potentiometer $(20 \mathrm{k} \Omega, 5 \mathrm{~W})$. The outlet of the pump was connected to a tube $9 \mathrm{~cm}$ in length and $1 \mathrm{~mm}$ in diameter, which was open to the atmosphere. The endotracheal tube cuff was connected to the pump by means of a flexible tubing $2 \mathrm{~m}$ in length and $2 \mathrm{~mm}$ in diameter (conventional pressure extension line for arterial catheter), allowing the pump to be placed at a convenient distance from the patient. This tube was ended with conventional connectors to maintain a permanently open cuff valve. The tubing and the cuff connected to the pump acted as a pneumatic low-pass filter that converted the oscillating pump flow into a constant pressure $\left( \pm 0.2 \mathrm{cmH}_{2} \mathrm{O}\right)$ inside the cuff. The potentiometer, which was calibrated in terms of pressure for this specific pump and tubing, allowed setting the $P$ cuff to $15-45 \mathrm{cmH}_{2} \mathrm{O}$.

The procedure was first tested at the bench to assess whether it was possible to keep a constant $P$ cuff under demanding conditions. An 8-mm endotracheal tube (Hi-Lo, Mallinckrodt Medical, Athlone, Ireland) was used to intubate and ventilate $\left(20 \mathrm{breath} \cdot \mathrm{min}^{-1}, 0.5 \mathrm{~L}\right.$ tidal volume; Servo ventilator 900C, Siemens, Solna, Sweden) a resistance-compliance lung model (Test Lung 190, Siemens) connected through an artificial trachea (nonrigid polyvinyl chloride (PVC) tube of $15 \mathrm{~cm}$ in length and $2.5 \mathrm{~cm}$ in internal diameter) [12]. Pressure at the outlet of the $P$ cuff regulator was recorded $(30 \mathrm{~Hz}$ low-pass filter; MP-45, Validyne, Northridge, CA, USA), while tracheal section at the level of the endotracheal cuff was modified by means of an actuator applied to the external wall of the artificial trachea.

The clinical feasibility of the $P$ cuff regulation procedure was assessed in eight sedated, intubated and mechanically-ventilated patients for $\geqslant 24 \mathrm{~h}$ before starting the study and they were consecutively admitted to the Respiratory ICU because of respiratory failure. The Ethical Committee of the Hospital approved the protocol and informed consent was obtained from patients' next-of-kin in all cases. In two of these patients, the valve built into the cuff tubing developed a considerable air leak (time constants of 3 and $10 \mathrm{~min})$. In these two patients, maintaining cuff inflation had required additional clamping of the cuff valve and frequent controls by the attending nurses. In each patient, the $P$ cuff regulator was applied for a period of $24 \mathrm{~h}$ and $P$ cuff was continuously measured (174PC28HD2, Honeywell, Freeport, IL, USA). The pressure signal was sampled, digitally filtered to eliminate the oscillations due to ventilator cycling, and stored on a computer.

\section{Results}

The bench test showed that the devised pressure regulation procedure was able to maintain $P_{\text {cuff }}$ regardless of the changes imposed in the tracheal diameter. Figure 2 a shows the time course of the $P$ cuff during baseline mechanical ventilation $(0-12 \mathrm{~s})$ and after a sudden decrease (12-43 s) and increase (43-60 s) in tracheal area in the conventional setting (i.e. when the cuff was inflated and kept closed by its own valve). As expected, $P$ cuff underwent a considerable increase/decrease (to 70 and $2 \mathrm{cmH}_{2} \mathrm{O}$ during expiration, respectively, from the baseline of $30 \mathrm{~cm}$ $\mathrm{H}_{2} \mathrm{O}$ ) as a result of a reduction/increase in tracheal area. The periodic changes $\left(20\right.$ cycles $\left.\cdot \mathrm{min}^{-1}\right)$ observed
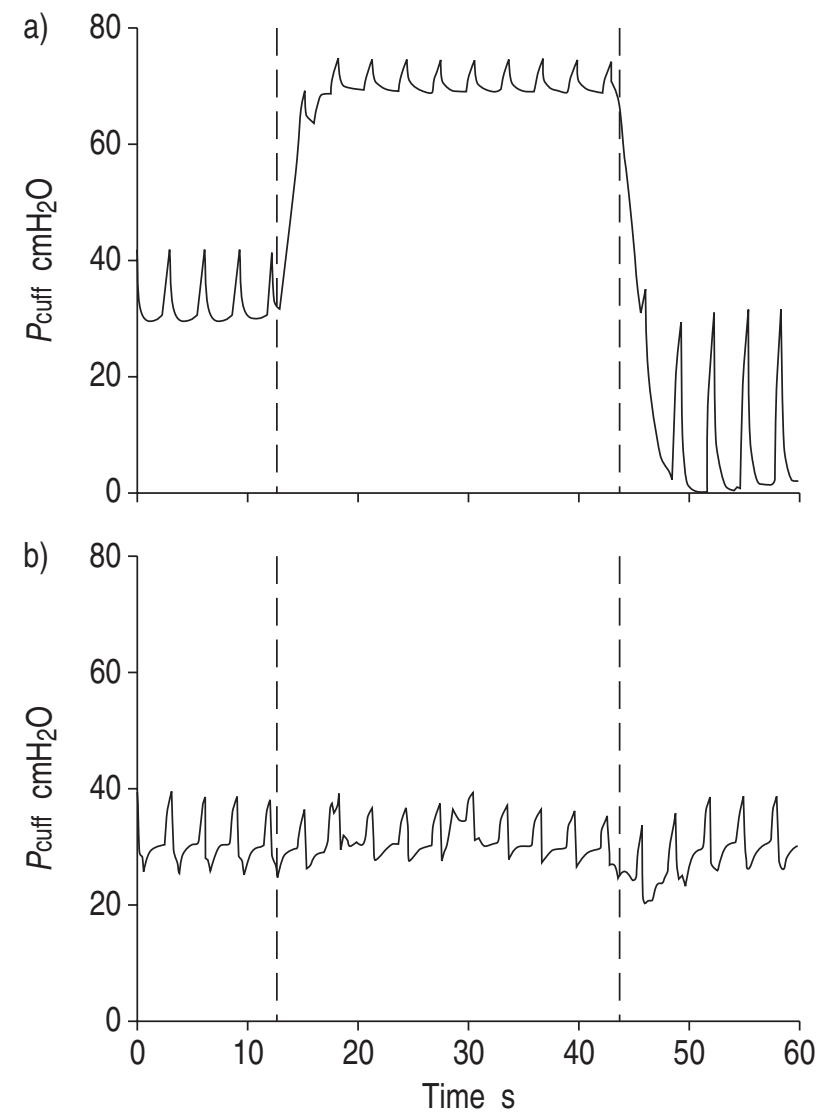

Fig. 2.-Endotracheal tube cuff pressure ( $P$ cuff) during mechanical ventilation of a respiratory system model, including a trachea with externally-controlled section. Time $0-12 \mathrm{~s}$ : baseline tracheal section; time 12-43 s: decreased tracheal section; time 43-60 s: increased tracheal section. a) Conventionally inflated cuff; b) application of the devised procedure to maintain cuff pressure. 


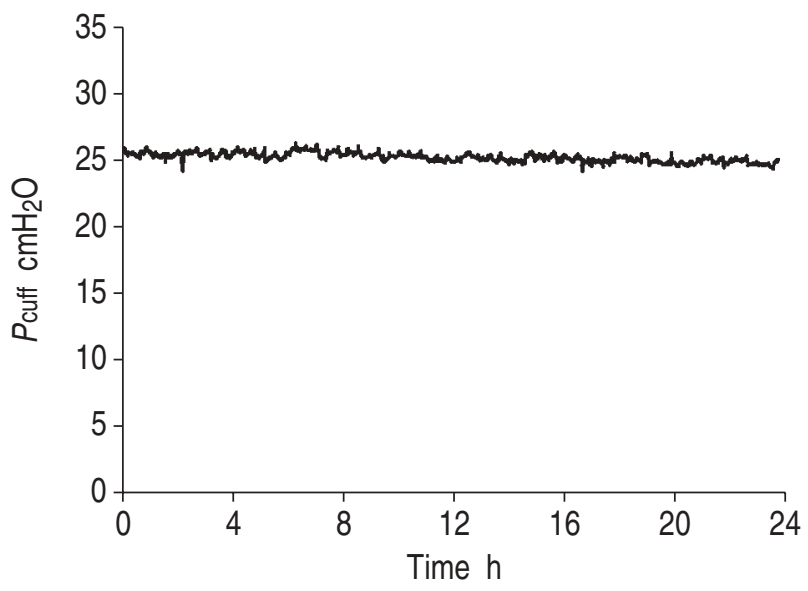

Fig. 3.-Example of the endotracheal tube cuff pressure ( $P$ cuff) during a 24 -h period of mechanical ventilation in a patient. $P$ cuff was digitally filtered to eliminate the tidal oscillations due to the ventilator cycling.

in $P$ cuff were induced by the change in tracheal pressure due to the ventilator cycling [13, 14]. By contrast, when the designed regulation system was used (fig. 2b), Pcuff remained constant as the artificial trachea was subjected to the same challenge.

The results obtained in the study of routine patients confirmed that the procedure devised was effective in regulating $P$ cuff in all the patients. Figure 3 shows the 24 -h recording of $P$ cuff in the patient whose cuff valve developed the greatest leak (i.e. the most demanding case in terms of keeping constant cuff inflation). Actual $P$ cuff was maintained at the target value within $\pm 2 \mathrm{cmH}_{2} \mathrm{O}$ over the 24 -h period in all the patients. The attending staff reported no particular incident with regard to $P$ cuff.

\section{Discussion}

The procedure that has been described and tested was effective in maintaining $P$ cuff during routine mechanical ventilation. As shown in figure 2 , the system exhibited a fast response under challenging conditions that would represent extreme changes in $P$ cuff in the clinical setting. The changes in cuff compression imposed in the bench study covered the ones that can reasonably be found in patients as a result of displacement of the endotracheal tube, a change in the tracheal wall tone, diffusion of anaesthetic gases [15] or hypothermic surgical procedures [16]. In particular, the fast response time of the devised procedure ensures its efficacy in compensating for leaks in the cuff, which usually have time constants much longer than the response time of the system. In fact, this was verified in two patients in whom the regulation system was able to compensate for considerable cuff leaks that had been managed with difficulty in the conventional setting (fig. 3).

From a practical viewpoint, which is of crucial importance for routine clinical application, the main feature of the procedure described is its simplicity.
First, it is easily implemented because it does not require expensive or sophisticated instrumentation (fig. 1). As it does not require electronic circuitry, specialised technical or engineering personnel, the system can be implemented in the ICU. Second, it is simple to operate since $P$ cuff is automatically and continuously regulated. Third, the procedure can be used to maintain $P$ cuff regardless of the specific ventilator or endotracheal tube employed.

The combination of simplicity and effectiveness is the most distinct characteristic of this procedure, when compared with alternative methods previously proposed to control cuff inflation. Indeed, most of these devices are not automatic and/or need frequent control by the attending staff [17-19]. Moreover, other devices operating in a more automatic and continuous way are complex, require the use of special and expensive equipment $[13,20,21]$ or require a special endotracheal tube (e.g. Lanz system; Mallincrodkt Medical) not available routinely. It is probable that these issues concerning complexity and cost could explain the lack of continuous automatic control of cuff inflation in clinical practice. The simple and cheap procedure the authors describe may facilitate the routine maintenance of adequate cuff inflation during mechanical ventilation.

The final step in the aetiopathogenesis of VAP is the aspiration of oropharyngeal secretions to the lower airways. The aspiration of pooled secretions between the endotracheal tube and the tracheal wall may be partly avoided using endotracheal tubes with a subglottic drainage aspiration lumen [22]. Continuous aspiration of subglottic secretions (CASS) may decrease or delay the incidence of VAP [23, 24]. However, CASS needs specific types of endotracheal tubes that may not be available at the time of intubation. Because the authors' devised procedure is potentially applicable in any clinical environment requiring intubation regardless of the specific type of ventilator or endotracheal tube used, it can be implemented at any time during the mechanical ventilation period without needing to replace the endotracheal tube, a risk factor for acquiring VAP [25]. In addition, CASS may be insufficient to prevent VAP when cuff inflation decreases, allowing pooled secretions to fall distally to the lower airways. Because cuff leaks are frequent in mechanically ventilated patients $[10,11]$, and loss of cuff inflation as a result of checking or maintaining pressure is a clear risk factor for VAP acquisition [11], maintaining the pressure of the cuff to avoid aspiration of pooled secretions is mandatory.

The authors' device would complement or substitute the use of subglottic aspiration tubes, and using this application alone or in combination with other simple measures, such as the semirecumbent position [26], could be useful in reducing the risk of ventilatorassociated pneumonia. In addition, it would be cheaper compared to other strategies or even to the use of endotracheal tubes with subglottic drainage. Consequently, a randomised study to test the authors' technique in the prevention of ventilator-associated pneumonia is warranted. 
Acknowledgements. The authors wish to thank M.A. Rodriguez for his technical assistance and the nursing staff of the Respiratory ICU of the authors' hospital for their cooperation.

\section{References}

1. Fagon JY, Chastre J, Hance AJ, Montravers P, Novara A, Gibert C. Nosocomial pneumonia in ventilated patients: A cohort study evaluating attributable mortality and hospital stay. Am J Med 1993; 94: 281-288.

2. Papazian L, Bregeon F, Thirion X, et al. Effect of ventilator-associated pneumonia on mortality and morbidity. Am J Respir Crit Care Med 1996; 154: 91-97.

3. Vincent JL, Bihari DJ, Suter PM, et al. The prevalence of nosocomial infection in intensive care units in Europe. Results of the European Prevalence of Infection in Intensive Care (EPIC) Study. JAMA 1995; 274: 639-644.

4. Kollef MH. The prevention of ventilator-associated pneumonia. N Engl J Med 1999; 340: 627-634.

5. Stauffer JL. Complications of translaryngeal intubation. In: Tobin MJ, ed. Principles and Practice of Mechanical Ventilation. New York, McGraw-Hill Inc., 1994: pp. 711-748.

6. Estes RJ, Meduri GU. The pathogenesis of ventilatorassociated pneumonia: I. Mechanisms of bacterial transcolonization and airway inoculation. Intensive Care Med 1995; 21: 365-383.

7. Craven DE, Steger KA. Epidemiology of nosocomial pneumonia: New concepts on an old disease. Chest 1995; 108: 1s-16s.

8. Seegobin RD, van Hasselt GL. Endotracheal cuff pressure and tracheal mucosal blood flow: endoscopic study of effects of four large volume cuffs. Brit Med $J$ 1984; 288: 965-968.

9. Deslee G, Brichet A, Lebuffe G, Copin MC, Ramon $\mathrm{P}$, Marquette $\mathrm{CH}$. Obstructive fibrinous tracheal pseudomembrane. A potentially fatal complication of tracheal intubation. Am J Respir Crit Care Med 2000; 162: 1169-1171.

10. Rashkin MC, Davis T. Acute complications of endotracheal intubation: relationship to reintubation, route, urgency, and duration. Chest 1986; 89: 165-167.

11. Rello J, Sonora R, Jubert P, Artigas A, Rue M, Valles J. Pneumonia in intubated patients: role of respiratory airway care. Am J Respir Crit Care Med 1996; 154: 111-115.

12. Young PJ, Rollinson M, Downward G, Henderson S.
Leakage of fluid past the tracheal tube cuff in a benchtop model. Br J Anaesth 1997; 78: 557-562.

13. Miller DM. A pressure regulator for the cuff of a tracheal tube. Anaesthesia 1992; 47: 594-596.

14. Guyton DC, Barlow MR, Besselievre TR. Influence of airway pressure on minimum occlusive endotracheal tube cuff pressure. Crit Care Med 1997; 25: 91-94.

15. Raeder JC, Borchgrevink PC, Sellevoid OM. Tracheal cuff pressures. The effects of different gas mixtures. Anaesthesia 1985; 40: 444447.

16. Souza-Neto O, Piriou V, Durand PG, et al. Influence of temperature on tracheal tube cuff pressure during cardiac surgery. Acta Anaesth Scand 1999; 43 333-337.

17. Abdelatti MO. A cuff pressure controller for tracheal tubes and laryngeal mask airways. Anaesthesia 1999; 54: 981-986.

18. Resnikoff E, Katz JA. A modified epidural syringe as an endotracheal tube cuff pressure-controlling device. Anesth Analg 1990; 70: 208-211.

19. Yoneda I, Watanabe K, Hayashida S, Kanno M, Sato T. A simple method to control tracheal cuff pressure in anesthesia and air evacuation. Anaesthesia 1999; 54: 975-980.

20. Petring OU, Adelhoj B, Jensen BN, Pedersen NO, Lomholt N. Prevention of silent aspiration due to leaks around cuff of endotracheal tubes. Anesth Analg 1986; 65: 777-780.

21. Morris JV, Latto IP. An electropneumatic instrument for measuring and controlling the pressures in the cuffs of tracheal tubes: The Cardiff Cuff Controller. J Med Eng Tech 1985; 9: 229-230.

22. Mahul PH, Auboyer C, Jospe R, et al. Prevention of nosocomial pneumonia in intubated patients: Respective role of mechanical sugglottic secretions drainage and stress ulcer prophylaxis. Intensive Care Med 1992; 18: 20-25.

23. Valles J, Artigas A, Rello J, et al. Continuous aspiration of subglottic secretions in preventing ventilatorassociated pneumonia. Ann Intern Med 1995; 122: 179-186.

24. Kollef MH, Skubas NJ, Sundt TM. A randomized clinical trial of continuous aspiration of subglottic secretions in cardiac surgery patients. Chest 1999; 116: $1155-1156$.

25. Torres A, Gatell JM, Aznar E, et al. Re-intubation increases the risk of nosocomial pneumonia in patients needing mechanical ventilation. Am J Respir Crit Care Med 1995; 152: 137-141.

26. Drakulovic MB, Torres A, Bauer TT, Nicolas JM, Nogue S, Ferrer M. Supine body position is a risk factor of nosocomial pneumonia in mechanically ventilated patients: a randomised clinical trial. Lancet 1999; 354: 1851-1858. 